\title{
Considerações teóricas sobre a terra como puro ativo financeiro e o processo de financeirização
}

\author{
Theoretical considerations on the land as pure \\ financial asset and the financialization process
}

MARIANA FIX*

LEDA MARIA PAULANI**,+

RESUMO: O presente artigo tem dois objetivos: 1) precisar conceitos que estão envolvidos na relação entre o mercado imobiliário e a financeirização da acumulação de capital; e 2) aprofundar a reflexão sobre as contradições existentes no tratamento da terra como puro ativo financeiro. Sempre que possível, exemplos concretos serão trazidos para ilustrar esse esforço conceitual.

PALAVRAS CHAVE: Mercado imobiliário; financeirização; capital portador de juros; mercadoria fictícia; capital fictício.

ABSTRACT: The present article has two goals: 1) to specify the concepts involved in the relationship between the real estate market and the financialisation of capital accumulation; and 2) to reflect more deeply on the contradictions of treating the land as a pure financial asset. In both cases, whenever possible, concrete examples will be brought to illustrate this conceptual effort.

KEYWORDS: Real estate market; financialization; interest bearing capital; fictitious commodity; fictitious capital.

JEL Classification: B51; O18; R30.

\footnotetext{
* Professora no Instituto de Economia da Unicamp, Campinas/SP, Brasil. E-mail: marianafix@gmail. com. ORCID https://orcid.org/0000-0003-2691-3222.

* Professora titular (senior) do Departamento de Economia da Faculdade de Economia e Administração da Universidade de São Paulo - FEA-USP, São Paulo/SP, Brasil. E-mail: paulani@usp.br. ORCID ID: 0000-0002-7306-5791.

+ Este artigo integra as atividades finais do estágio pós-doutoral desenvolvido por Mariana Fix, sob a supervisão da professora Leda Paulani, na FEA-USP, correspondente ao Prêmio CAPES de Tese edição 2012, outorgado pela Coordenação de Aperfeiçoamento de Pessoal de Nível Superior (CAPES) pelo trabalho intitulado "Financeirização e transformações recentes no circuito imobiliário". A tese foi desenvolvida no Instituto de Economia da Unicamp sob a orientação do professor Wilson Cano. Os temas tratados pelo artigo integram o projeto de pesquisa Financeirização e Rentismo: Considerações Teóricas e Observações sobre o caso Brasileiro, de Leda Maria Paulani, que conta com o apoio financeiro do CNPq por meio de Bolsa de Produtividade em Pesquisa. Submetido: 4/Junho/2018; Aprovado: 27/Fevereiro/2019.
} 


\section{INTRODUÇÃO}

Este trabalho trata da participação do mercado imobiliário ${ }^{1}$ no processo de financeirização da acumulação de capital. Esse mercado é entendido aqui como frente permanente de valorização, sobretudo na atual quadra histórica, marcada pela sobreacumulação, ou seja, pela produção de capital em excesso em relação às possibilidades de aplicação produtiva.

A singularidade desse mercado está, como veremos, em reunir numa única atividade produtiva as três formas sob as quais a mais-valia aparece: o lucro (valor excedente produzido no canteiro de obras), o juro (parcela do valor excedente que remunera quem fornece o funding, ou seja, os recursos monetários, para a produção) e a renda (sobrevalor futuro capitalizado embutido no preço da terra).

A produção do espaço construído exibe uma relação imediata com o mercado financeiro, seja pela necessidade de financiar a produção, seja pela necessidade de viabilizar o consumo. Além disso, a terra, elemento fundamental do setor imobiliário, tem seu preço determinado tal como os ativos financeiros, ou seja, pelo valor presente das rendas futuras esperadas. ${ }^{2}$ É preciso, portanto, investigar que alterações produz, sobre um mercado já tão diretamente relacionado às questões financeiras, a emergência de um processo a que se dá o nome de financeirização.

Assim, a primeira seção do artigo retoma conceitos básicos referentes a esse mercado e a esse processo, enquanto a segunda dá especial destaque às contradições envolvidas no tratamento da terra como puro ativo financeiro. Cabe lembrar que trataremos aqui apenas dos traços mais gerais do problema, não estando em nosso escopo o fato de a forma de inserção dos países periféricos no processo de financeirização diferir daquela experimentada pelos países centrais, alterando-se por isso também, em cada um desses espaços, as consequências da imbricação entre setor imobiliário e financeirização. O tratamento teórico da questão é suficientemente complexo e demanda um artigo à parte. Sempre que necessário, porém, algumas observações serão efetuadas considerando-se os exemplos concretos trazidos para ilustrar o esforço teórico aqui efetuado.

\footnotetext{
${ }^{1}$ Utilizamos o termo "mercado imobiliário" por ser de uso mais corrente e remeter de modo mais imediato às questões a serem discutidas. Contudo, como ficará claro, não se trata aqui apenas da esfera da circulação, ou seja, da compra e venda de imóveis, mas também da esfera da produção, ou da produção do espaço construído. Sendo assim, o termo "setor imobiliário" também será eventualmente utilizado.

${ }^{2}$ A questão remete, de imediato, a um dos conceitos seminais da economia política, a renda da terra, bastante desenvolvido em Ricardo e em Marx. No que concerne à relação entre o setor imobiliário e a renda da terra, o debate nacional dispõe já de uma vasta e rica produção: Carlos (2011), Ribeiro (1997), Rodrigues (2014), Maricato (org.) (1979), Seabra (1987), Villaça (1985), dentre outros.
} 


\section{FINANCEIRIZAÇÃO E MERCADO IMOBILIÁRIO: RETOMANDO CONCEITOS}

\section{Financeirização: a construção do conceito}

A assim chamada financeirização do processo de acumulação de capital passou a integrar o rol dos temas mais discutidos pelos marxistas a partir de meados dos anos 1990. ${ }^{3}$ Intrincada por definição, a questão foi objeto de muita discussão teórica, gerando uma produção acadêmica crescente. Um problema adicional para os marxistas está no fato de as assim chamadas "teses da financeirização" poderem ser facilmente confundidas com posturas keynesianas, dada a relativa proximidade entre as teorias monetárias de Marx e Keynes e a conhecida irritação do último com os falcões das finanças. Assim, na discussão em torno dessa questão, a utilização de termos externos ao léxico marxista causava ainda mais estranhamento e antipatia do que o normal.

De todos os teóricos que se debruçaram sobre essa temática, François Chesnais foi o que mais traduziu, na sequência de seus trabalhos, esse caminho sinuoso e cheio de obstáculos. Em seu livro lançado em 1996, La Mondialisation Financière, o autor faz uso explícito dos conceitos da chamada "Teoria da Regulação". Daí a afirmação de que o capitalismo estaria presenciando "um regime de acumulação com dominância da valorização financeira". ${ }^{4}$ No livro seguinte, La Finance Mondialisée, de 2004, não há mais menção a esses termos e o que está colocado no centro de sua análise é o conceito marxista de capital portador de juros. No livro de 2016, Finance Capital Today, ele cita explicitamente o abandono dessas noções e do approach regulacionista (p. 14). Nesse mesmo livro, ele cunha novos conceitos em torno da ideia do capital financeiro (pp. 5-9) e, para dirimir algumas dúvidas que ainda persistem, define o que se deve afinal entender por financeirização (pp. 14-16). No presente trabalho utilizaremos essa última definição de financeirização, não só pela concordância que temos com ela, mas também porque Chesnais, em paralelo a sua reflexão teórica, nunca descuidou da investigação empírica sobre o

\footnotetext{
${ }^{3}$ O livro de François Chesnais, La Mondialisation du Capital, publicado na França em 1994, traz já um capítulo todo dedicado a essa discussão. De modo presciente, Harvey deu papel central ao capital portador de juros e às finanças em seu livro Limits to Capital, publicado em 1982. Mas tratava-se de um livro teórico, não um livro sobre capitalismo contemporâneo, de modo que passou despercebido por muito tempo (sua segunda edição só apareceu em 2006). No Brasil, ainda que num escopo teórico e temático mais amplo, mas de modo também premonitório, José C. Braga dá a devida importância à questão em sua tese de doutorado defendida no IE-Unicamp em 1985 (publicada em livro pela Editora do IE-Unicamp em 2000).

${ }^{4}$ Regime de acumulação é um dos conceitos-chave da Teoria da Regulação (o outro é o conceito de modo de regulação), tal como se expressa no trabalho original de Michel Agliettá, Regulation et Crises $d u$ Capitalisme, de 1976. Apesar de partir de uma crítica pesada à teoria neoclássica e de forjar seus conceitos originais tendo por base o conceito marxista de modo de produção, a teoria é vista como excessivamente eclética por muitos marxistas. Uma boa resenha dessa teoria está em Boyer (1990).
} 
capitalismo contemporâneo, o que seguramente contribui para a propriedade dessa definição. ${ }^{5}$

A financeirização, afirma Chesnais, "diz respeito à disseminação profunda e geral das características do capital portador de juros, tal como identificadas por Marx no Livro III de O Capital, no sistema como um todo" (2016, pp. 15-16, tradução nossa). A atuação desse capital, no contexto da continuidade de uma crise de sobreacumulação, tem inúmeras consequências e está "organicamente incorporada na fábrica da vida social” (Ibidem, p. 16). Para nosso autor, essa onipresença do capital portador de juros não pode, por isso, ser dissociada da consideração do elevadíssimo grau de concentração e centralização de capital hoje presentes no processo de acumulação. ${ }^{6} \mathrm{~A}$ formação acelerada de grandes blocos de capital produtivo por meio do processo de centralização, que predomina em fases de crise como a atual, vai ocorrendo em paralelo ao agigantamento dos mercados financeiros e por meio da utilização de sofisticados expedientes financeiros, como, por exemplo, os fundos de private equity e suas operações de leveraged buy outs (LBOs). ${ }^{7}$ Segundo Chesnais (2016, p. 16), isso vai contribuindo para o reforço do processo de financeirização uma vez que implica a continuidade do crescimento da riqueza financeira (e fictícia) ${ }^{8}$ em escala sempre maior do que a do crescimento da riqueza real e a intensificação a um grau inédito da pretensão do capital financeiro à autonomia, detectada por Marx.

\section{Capital Portador de Juros e Ativos de Capital Reais e Financeiros}

Se Chesnais está certo, a dificuldade com o conceito de financeirização reside, principalmente, na dificuldade com o conceito de capital portador de juros. O que ele significa de fato? Significa que o capital se transforma numa mercadoria. A

\footnotetext{
${ }^{5}$ Os resultados desses trabalhos aparecem, entre outros, em Chesnais (org.), 1998, 2005; Chesnais et al. (org.), 2010; Chesnais, 2016.

${ }^{6}$ Relembrando, com Marx: concentração de capital diz respeito ao crescimento do capital graças à operação normal do processo de reprodução ampliada, enquanto centralização de capital está relacionada a esse mesmo crescimento, mas pela incorporação, por parte de capitais maiores e/ou mais estruturados, de capitais menores e/ou menos estruturados (movimento esse que é cada vez mais efetivado por meio de práticas predatórias viabilizadas e incentivadas por mecanismos financeiros de crescente sofisticação). Os dois processos estão o tempo todo presentes, mas nas fases de ascenso cíclico predomina o primeiro, enquanto nas fases de recessão o protagonismo é do segundo. Os processos de fusão de grandes grupos de capital, elevando seu poder de monopólio, enquadram-se no último dos conceitos.

${ }^{7}$ Private equities são títulos de participação em empresas já estabelecidas, mas ainda não cotadas em bolsa (ou seja, de capital fechado). Os fundos de private equity são esquemas coletivos de investimento nesse tipo de título. As LBOs são transações que podem transferir o controle de uma empresa a um grande bloco de capital ou a grandes investidores por meio da utilização alavancada do fluxo de caixa dessa empresa como colateral na emissão de títulos de dívida. Voltaremos ao tema das private equities mais à frente.
}

${ }^{8}$ Discutiremos esses conceitos mais à frente. 
capacidade de, graças à sua circulação, engendrar a produção de um valor excedente, é posta à venda, e o capital se transforma em capital portador de juros. Essa transmutação, que transforma o capital em mercadoria, sendo o juro seu "preço", coloca essa mercadoria especial num circuito próprio, que não se confunde com aquele que abriga a circulação das mercadorias ordinárias.

Assim, ao ser lançado na circulação como mercadoria, o capital, agora transformado em capital portador de juros, vai integrar o movimento de circulação das mercadorias especiais, cujo valor de uso é o de "produzir valor" e, no caso do capital portador de juros, cujo "valor" (que neste caso é igual a "preço") é o juro. Nesse circuito são objeto de transação os ativos, ou estoques de riqueza (no circuito das mercadorias triviais, o que se compra e se vende são valores de uso, de maior ou menor duração, destinados a satisfazer necessidades humanas e não a produzir valor adicional, ou seja, alimentos, roupas, remédios, livros, móveis etc.). ${ }^{9}$ Além de funcionar como meio de circulação de mercadorias ordinárias e como capital monetário (aquele que compra meios de produção e força de trabalho), "na base da produção capitalista", lembra Marx (1984, p. 255), qualquer soma de dinheiro ganha "um valor de uso adicional, a saber, o de funcionar como capital" e é nessa condição que ele se transforma em mercadoria. Sem esse valor de uso adicional, sua posição como objeto de compra e venda não faz sentido, porque ele funciona então apenas como meio de compra ou meio de pagamento e não pode, por isso, por definição, ter um "preço".

No circuito dessas mercadorias especiais, circulam ativos de capital reais e financeiros. Uma parcela substantiva dos ativos reais, classificados em geral como capital fixo (máquinas, equipamentos, instalações, edifícios e infraestrutura), possui um valor de uso efetivo que é produto do trabalho concreto. Mas esse grupo envolve também as porções do globo sobre as quais agentes privados detêm monopólio, podendo se transformar em objeto de transação, ou seja, os terrenos. Neste caso, o valor de uso efetivo não é produto do trabalho concreto nem é reproduzível pelo trabalho, mas está associado à terra enquanto "presente da Natureza”. Podemos dizer, acompanhando Harvey (2006, pp. 333-341), que a terra tem um duplo valor de uso: os terrenos são a base para a reprodução material e para a extração (funcionando então como meio de produção - agricultura, indústria extrativa), e são também elementos necessários de toda a produção e atividade humana (fun-

\footnotetext{
${ }^{9} \mathrm{O}$ termo "ativo" vem da contabilidade empresarial e diz respeito, como já assinalado no texto, aos estoques de riqueza, sob as mais variadas formas, que uma empresa detém num determinado momento do tempo. Na data do balanço, por exemplo, 31 de dezembro de 20XX, todos os ativos da companhia são mensurados monetariamente e relacionados, sejam eles ativos reais tangíveis (imóveis, edifícios, máquinas, equipamentos, estoques de bens), intangíveis (patentes, marcas), ou financeiros (créditos a receber, aplicações financeiras), além de meios de pagamento (dinheiro corrente e depósitos à vista nos bancos comerciais). No approach da economia política, ativos são sinônimos de capital, ou seja, bens com potencial para possibilitar a apropriação de valor excedente futuro, seja por sua utilização na produção, seja pelos direitos de propriedade que eles configuram.
} 
cionando então como espaço, como lugar e fazendo parte, por isso, daquilo que Marx chama de condições objetivas do processo de trabalho).

Ambos, no entanto, ou seja, tanto o capital fixo stricto sensu, quanto os terrenos, são ativos de capital (reais) e circulam como capital. Um ativo fixo, uma máquina, é capital porque sua utilização engendra, para seu proprietário, a produção de valor excedente, que vai aparecer como lucro. Um terreno é capital porque sua utilização engendra, para seu proprietário, a possibilidade de se apropriar de uma parcela do valor excedente produzido, que vai aparecer como renda da terra.

\section{Renda da Terra e a Terra enquanto Ativo}

Enquanto ativo real, a terra tem, entretanto, algumas peculiaridades, que a tornam singular. Em primeiro lugar, ela integra também aquilo que Marx chamou de fundo de consumo, ou seja, o conjunto daqueles bens de maior durabilidade que no entanto não funcionam como capital, mas simplesmente garantem a reprodução material da vida social, a dos trabalhadores em particular. As residências fazem parte desse conjunto de bens, que se apresentam em geral como mercadorias. Elas constituem seu item mais oneroso e evidentemente não existem sem um terreno sobre o qual elas possam ser erguidas. O fato de a terra ser condição de vida para a força de trabalho coloca o trabalhador em posição antagônica à apropriação da renda da terra, em luta para controlar suas condições de existência no local de residência (Harvey, 2006, pp. 29-82). Os conflitos relacionados com a produção e o uso do meio ambiente construído são uma faceta importante da luta de classes, como argumenta Harvey em diversos escritos (Ibidem, pp. 6-7). Mas é preciso também lembrar que, em alguns casos, como acontece amiúde nos países periféricos, apesar de os elementos desse fundo se apresentarem como mercadorias, sua constituição, no que tange às residências, acaba por se dar ao largo do mercado formal, por meio de expedientes como o da autoconstrução. A extrema exploração da força de trabalho nesses espaços não contempla as residências na cesta básica de bens que constitui o valor dessa força, donde o surgimento de expedientes alternativos ao mercado.

A segunda peculiaridade que singulariza a terra como ativo é que, apesar de ela ser um ativo real e fazer parte daquilo que Marx denominou "as condições objetivas do processo de trabalho" ${ }^{10}$ ela é uma mercadoria fictícia. Como não pode ser reproduzida pelo trabalho humano, não possuindo, portanto, valor, a terra, na base da produção capitalista, tem seu preço determinado pela capitalização das rendas futuras esperadas de seu uso. A renda da terra é, portanto, a forma que coloca a terra como propriedade efetivamente capitalista (Marx, 1985, p. 126). A terra é assim uma mercadoria fictícia, que integra o conjunto dos ativos de capital que podem ser chamados de reais. Mas ela pode se transformar também num capital fictício. Vejamos.

${ }^{10}$ Ver a respeito O Capital, Livro I, capítulo 5, primeira seção. 


\section{Terra e Capital Fictício}

Comecemos por esclarecer o que é capital fictício. Resumidamente podemos dizer com Herrera $(2015$, p. 9), que o princípio básico do capital fictício é "a capitalização de uma renda derivada de um sobrevalor futuro", lembrando que, no livro III de O Capital, Marx diz: "a formação do capital fictício chama-se capitalização" (1985, p. 11). Ora, a capitalização depende da taxa de juros, de modo que sem a posição do capital como mercadoria e, portanto, sem a consequente existência dessa forma de apropriação de mais-valia (o juro), o capital fictício tampouco poderia existir. E por que Marx chama de fictícios os ativos de capital que são resultado da operação desse princípio? Porque eles funcionam ao revés.

O capital real, como sabemos, é um movimento, o movimento de valorização do valor. Nos ciclos que constituem esse movimento, ele aparece em suas figuras de capital monetário (utilizado como meio de circulação na compra de meios de produção e força de trabalho), capital produtivo (incorporado nesses meios de produção e nessa força de trabalho postos em funcionamento para serem consumidos) e capital mercadoria (incorporado nos bens produzidos, já engordado da mais-valia e pronto para retornar à figura de capital monetário). A valorização desse capital real depende do tempo da produção e das mercadorias que dele resultam. Sem o tempo da produção e sem a produção que se efetiva durante esse tempo, o capital é anômico, indeterminado, não pode se definir. O montante de dinheiro original é apenas um tanto de meio circulante ordinário, que pode ter qualquer uso.

O capital fictício inverte essas determinações. Em primeiro lugar, ele herda de sua figura originária, o capital portador de juros, a capacidade de transformar o movimento da valorização numa coisa, colapsando o tempo e plasmando a valorização nessa coisa. Em segundo lugar, não é o valor monetário inicial posto em movimento que engendra, através da produção, o valor excedente e o constitui como capital, mas o contrário, é o valor excedente pressuposto num determinado período de tempo que, trazido de frente para trás pela taxa de juros, gera seu valor e garante sua posição como capital. Em terceiro lugar, por consequência, o capital fictício nunca abandona a figura de capital monetário: como não precisa passar pelo calvário da produção, tampouco precisa abandonar a forma monetária. Ele cresce magicamente com o tempo, por força de algum tipo de "aplicação financeira".

Assim, a terra, apesar de ser uma mercadoria fictícia, não é, por sua própria natureza, um capital fictício. Em primeiro lugar, o fato de a terra nunca poder abandonar sua forma concreta de espaço, porção do território, coloca já uma primeira diferença. Em segundo lugar, tal como as máquinas e outros tipos de capital fixo, o surgimento de valor excedente que sua propriedade privada engendra só se efetiva se ela estiver diretamente articulada com o processo produtivo. A renda, que constitui sua forma específica de se apropriar de valor excedente, só aparece junto com a produção, ainda que sua condição de elemento ou instrumento de produção não seja a base para a apropriação de tal renda, mas sim o poder monopólico exercido por seus proprietários. Finalmente, apesar de a determinação de seu preço 
se dar de forma similar àquela observada para os capitais fictícios, isso acontece porque, diferentemente de outros ativos reais (como as máquinas, por exemplo), a terra é um ativo não reproduzível. Contudo, no caso da terra, o resultado contábil da capitalização das receitas futuras não é tudo a que ela se reduz como capital (como acontece no caso dos capitais fictícios). Isso é apenas seu preço. Sustentando esse preço, temos um pedaço de terra, algo efetivamente real. Seu valor de uso não se resume à sua capacidade de "produzir valor", mas conta também com sua capacidade de funcionar como meio de produção, como condição objetiva do processo de trabalho ou como elemento do fundo de consumo.

Contudo, Harvey vai argumentar que é na "crescente tendência a tratar a terra como puro ativo financeiro" (2006, pp. 347 , grifo nosso) que "encontra-se a chave para o modo e o mecanismo de transição para a forma puramente capitalista da propriedade privada da terra". Para ele, se a terra é livremente comercializada, o que se compra e se vende, tal como acontece com os capitais fictícios, é justamente o direito do proprietário ao recebimento periódico de uma renda e, nesse caso, "o comércio da terra fica reduzido a um braço especial da circulação do capital portador de juros" (Harvey, 2006, p. 347).

Para Marx, como já mencionado, a forma econômica na qual a propriedade da terra se efetiva no capitalismo é a renda, porque ela pressupõe a extração de valor excedente a partir da posição da força de trabalho como mercadoria. Para Harvey, para que a terra alcance a forma puramente capitalista de propriedade é preciso um passo a mais: é preciso que a comercialização da terra se dê exclusivamente em função de sua capacidade de garantir direito a essa renda e isso implica tratá-la como ativo puramente financeiro, como capital fictício.

Podemos concordar com Harvey e acrescentar que, quando a terra é tratada como ativo puramente financeiro, o que acontece é que a forma de determinação de seu preço prevalece sobre sua especificidade de ser um ativo real e de ter um valor de uso efetivo. Assim, a terra transforma-se de ativo real em ativo financeiro, de elemento necessariamente constituinte do capital produtivo em capital fictício.

\section{Especulação e Securitização}

Dadas as peculiaridades da terra como ativo e a forma "financeira" da determinação de seu preço, a capitalização está, por assim dizer, no DNA da terra enquanto mercadoria, ou seja, não é uma faceta introduzida pela financeirização. $\mathrm{Na}$ realidade, como vimos, a singularidade desse mercado está em que ele reúne, numa única atividade produtiva, as três formas sob as quais a mais-valia aparece: o lucro (valor excedente produzido no canteiro de obras), o juro (parcela do valor excedente que remunera quem fornece o funding para a produção) e a renda (sobrevalor futuro capitalizado embutido no preço da terra).

Mas, para responder adequadamente à pergunta a respeito das imbricadas relações entre a financeirização e este mercado tão especial, falta-nos ainda um elemento. Como dissemos anteriormente, a terra como mercadoria integra a esfera de circulação dos ativos de capital, sejam eles reais ou financeiros. As compras e 
vendas que ocorrem aí estão, portanto, naturalmente sujeitas ao fenômeno da especulação, ou seja, às iniciativas de variado teor destinadas à obtenção de ganhos na circulação. Os ganhos realizados nas Bolsas de Valores, quando se compra hoje a preços reduzidos ações que amanhã são vendidas por preços mais elevados, são típicos ganhos especulativos. Eles não estão relacionados, nem direta, nem indiretamente, à geração de valor novo ou valor excedente, mas tão somente às mudanças de mãos de determinados estoques de riqueza, sendo que cada agente visa, com essas operações, valorizar os seus próprios estoques.

Vale enfatizar que, apesar de utilizarmos para as operações especulativas os mesmos termos ("valor", "valorizar"), a "valorização" aqui envolvida decorre simplesmente dos ganhos especulativos, ou seja, dos ganhos obtidos na esfera da circulação ao se comprar barato e se vender caro (e não da produção de valor excedente novo). Porém, quando o ativo em questão é a terra, a situação se altera um pouco. Como seu preço é resultante da capitalização das rendas futuras esperadas, esse ganho na esfera da circulação pode ser visto como estando associado também à elevação da renda, no caso da renda absoluta. ${ }^{11}$ Em outras palavras, quando, numa operação especulativa, um terreno é retido até que seu preço de mercado atinja aquilo que seu proprietário deseja para aliená-lo, esse comportamento implica simultaneamente a elevação da renda futura esperada do uso capitalista do referido terreno (ou ninguém o compraria por esse preço aumentado). Se estamos falando de espaço urbano, esse movimento, além de enriquecer o proprietário do terreno, levará inevitavelmente a preços mais elevados para as futuras construções que aí se ergam, os quais pressupõem aluguéis futuros igualmente mais elevados.

Mas há uma outra forma por meio da qual a atividade especulativa pode afetar o imobiliário. Ela está relacionada à abertura de capital das empresas ligadas ao setor. Essa alteração tende a colocar sobre as empresas a pressão geral que a concorrência franqueada nas Bolsas entre os capitais de diferentes setores exerce sobre resultados, rendimentos e distribuição de lucros (dividendos), aumentando dessa forma a pressão por ganhos especulativos ainda maiores. Para que as empresas do setor imobiliário sejam bem-vistas nas Bolsas, passa a ser importante, por exemplo, a posse de estoques de terrenos (bancos de terra), o que evidentemente faz crescer a especulação.

No caso do Brasil, a partir de 2004, quando muitas empresas, de diversos ramos, passaram a abrir seu capital, a possibilidade de captar recursos por meio da oferta de ações nas Bolsas de Valores passou a motivar várias incorporadoras, a maioria de estrutura familiar, a seguirem esse caminho. Em curto período de tempo, a maior parte das grandes empresas imobiliárias fez suas Ofertas Primárias de Ações na Bovespa. Os efeitos complexos decorrentes desse passo diferem, no circuito imobiliário, daqueles de outros setores, justamente pelas singularidades discutidas neste artigo.

\footnotetext{
${ }^{11}$ Para maior precisão quanto ao termo, extraído da seção 6 do Livro III de O Capital, ver Paulani (2016).
} 
As empresas que abriram capital na Bolsa passaram por mudança patrimonial relevante. Várias delas receberam novos fluxos de investimentos ainda antes da abertura de capital, por meio dos fundos de private equity. As empresas gestoras desses fundos captam recursos financeiros de investidores e compram a participação minoritária de uma empresa ou assumem o controle do negócio. Depois de algum tempo elas procuram sair do investimento e realizar os ganhos por meio de venda da participação, pela abertura de capital em Bolsa de Valores e pelo repasse das cotas e ações para os investidores. ${ }^{12}$ Vários fundos desse tipo compraram participações em empresas do setor imobiliário brasileiro nessa época, participaram da preparação para a oferta primária inicial, e depois foram desmobilizando seus ativos ao longo dos anos.

Em várias empresas, no entanto, ao contrário do que se poderia esperar, os antigos proprietários (ou suas famílias) permaneceram como os maiores acionistas, ainda que com presença significativa, durante o boom imobiliário, de capital internacional. Importante observar ainda que esse processo só ocorreu depois de uma série de medidas do governo federal no sentido de ampliar o crédito imobiliário, somada às mudanças no marco regulatório, que sustentaram em conjunto o boom imobiliário ocorrido a partir de 2006. Elevou-se o uso dos fundos existentes (Fundo de Garantia por Tempo de Serviço, FGTS, e Sistema Brasileiro de Poupança e Empréstimo, SBPE) com taxas de juros menores, complementados com recursos do orçamento geral da União (OGU) e a redução da alíquota de impostos em obras do Programa Minha Casa, Minha Vida (PMCMV). ${ }^{13}$ Ou seja, foi uma combinação de fundos públicos e semipúblicos, de subsídios diretos e indiretos, que completou o circuito imobiliário e jogou óleo nas engrenagens "do mercado". Aqui, como em outros casos, temos evidências de que o acirramento da natureza financeirizada do setor imobiliário pela intensificação do processo de financeirização, de que a abertura de capital é um expediente típico, pode ter características e consequências muitos diferentes quando o espaço em questão é um país periférico.

Mas nem todos os ativos de capital são, por sua natureza, objeto de especulação. As ações (ativo financeiro e capital fictício), como indicado acima, são; os terrenos e imóveis (ativos reais tratados como capital fictício) também são; mas um título público (ativo financeiro, capital fictício), por exemplo, não é; um crédito bancário associado a financiamento de capital fixo (ativo financeiro, capital portador de juros) tampouco é. Mas tudo muda quando se organizam mercados secundários para esses ativos. Os mercados secundários transformam todo ativo de capital, quaisquer que sejam sua natureza e especificidades, em objeto de especulação e potencializam o caráter naturalmente especulativo apresentado por alguns tipos de ativos.

A securitização consiste justamente na transformação do ativo financeiro re-

\footnotetext{
${ }^{12}$ Quando a operação não é bem-sucedida, a gestora tem que assumir o prejuízo e arcar com a falência ou fechamento da empresa.

${ }^{13}$ Para maiores informações sobre esse processo, ver Fix (2011), entre outros.
} 
sultante de uma relação débito/crédito original (a primeira rodada de atuação do capital como mercadoria) em algo novamente transacionável nos mercados, agora secundários (uma segunda rodada de atuação do capital como mercadoria, assentada no mesmo objeto). Apesar de existir desde meados dos anos 1970, esse processo ganha impulso a partir de meados dos anos 1990 e é hoje um dos elementos mais característicos da financeirização. Diz-se, por isso, que a crise financeira internacional de 2007-2008 foi a primeira crise de crédito "pós-securitização". ${ }^{14}$

Em relação a essa grande crise cabe lembrar que ela está relacionada a todas as questões aqui discutidas. Em 1982, uma comissão instituída pelo presidente Ronald Reagan sugeriu um estímulo à casa própria por meio da redução de regulações locais de densidade, zoneamento e crescimento, agilizando os processos de aprovação de projeto (Galster, 2008, p. 9). Recomendou ainda a redução da dependência em relação aos credores especializados, a reestruturação da indústria da poupança (thrift), a utilização de hipotecas com taxas ajustáveis, a redução das restrições em relação aos títulos lastreados em hipotecas (MBS) e crescente ênfase no mercado secundário de hipotecas. O Alternative Mortgage Transactions Parity Act (AMTPA), ${ }^{15}$ do mesmo ano, legalizou as hipotecas com taxas flutuantes, pagamentos tipo balão, ${ }^{16} \mathrm{e}$ várias outras transações que anteriormente violavam as leis estaduais de usura. A adoção de todas essas medidas, em nome da resolução do problema habitacional, propiciou o crescimento da securitização, com a emissão de títulos financeiros lastreados em imóveis. Em 2006, o relatório Loosing Ground, do Center for Responsible Lending, denunciava o caráter "predatório" dos empréstimos subprime e previa a execução hipotecária de mais de 2,2 milhões de imóveis. Nos anos seguintes, o aumento da inadimplência, no contexto do crescimento da taxa de juros, foi seguido de milhões de execuções hipotecárias, superando em muito as previsões ao atingir um total de 4,6 milhões em $2010 .{ }^{17}$

Ainda com relação à importância da securitização para as questões aqui discutidas, vale lembrar que foi instituído no Brasil, em 1997, sob o apoio incondicional da Associação Brasileira das Entidades de Crédito Imobiliário e Poupança (Abecip), o Sistema de Financiamento Imobiliário (SFI), que justamente previa, em sua

\footnotetext{
${ }^{14}$ A informação está em Chesnais (2016, p. 220).

${ }^{15}$ Disponível em https://www.gpo.gov/fdsys/pkg/STATUTE-96/pdf/STATUTE-96-Pg1469.pdf. Acesso em 4 de junho de 2018.

${ }^{16}$ Para um exemplo concreto de práticas desse tipo ver Wyly et ali, 2006. A referência ao "balloon payment" encontra-se na seção 341 do AMTPA, citado acima. A definição está disponível em diversos glossários, entre eles este do estado de Nova Jersey: “A mortgage with periodic installments of principal and interest that do not fully amortize the loan. The balance of the mortgage is due in a lump sum at a specified date, usually at the end of the term" (http://www.state.nj.us/dobi/division_consumers/finance/ hoa03define.htm\#balloon). Acesso em 4 de junho de 2018).

17 Dados disponível em ftp://ftp.census.gov/library/publications/2011/compendia/statab/131ed/ tables/12s1194.pdf. Acesso em 4 de junho de 2018. Para uma discussão mais detalhada desse processo, ver Fix (2011).
} 
arquitetura market oriented, a securitização de recebíveis imobiliários. ${ }^{18} \mathrm{O}$ modelo norte-americano foi apontado como referência principal: "É o que fazem os Estados Unidos com a Federal National Mortgage Association (Fannie Mae), com administração privada, ações negociadas em Bolsa e capacidade financeira para dar liquidez às operações." ${ }^{19}$ Esse modelo seria o mais apropriado para o Brasil "por não ter nenhuma dependência de funding direto ou de direcionamento obrigatório", ${ }^{20}$ diferentemente do Sistema Financeiro de Habitação (SFH), que define percentuais a serem destinados a cada tipo de financiamento. O suposto fracasso do SFH e a crise do financiamento público foram as justificativas mais recorrentes encontradas em vários documentos da época para a introdução desse mecanismo no mercado brasileiro. A grande novidade do SFI em relação aos expedientes até então existentes seria a possibilidade de captar fundos junto ao mercado de capitais. Além disso, no lugar do direcionamento dos recursos da poupança (a exigibilidade de aplicação em crédito imobiliário), a alocação seria definida por mecanismos de mercado.

Alguns instrumentos foram especialmente desenhados nesse contexto, como os Certificados de Recebíveis Imobiliários (CRIs), as Cédulas de Crédito Imobiliário (CCI) e as Letras de Crédito Imobiliário, enquanto outros, já existentes, foram reformulados, como as Debêntures, as Letras Hipotecárias e as Cédulas de Crédito Bancário. Os CRIs são apresentados pela norma técnica do Conselho Monetário Nacional (CMN) como um instrumento assemelhado aos mortgage backed securities (MBS) norte-americanos, emitidos por empresas como Fannie Mae e Freddie Mac. ${ }^{21}$

Segundo, Royer (2014), no entanto, "o CMN, que regulamenta o SFH, passou a emitir, praticamente ano a ano, desde 1998, uma série de resoluções que levaram os CRIs e outros títulos semelhantes a captar recursos desse sistema, inclusive aqueles que deveriam ser destinados ao atendimento da baixa renda, como o FGTS". 22 Assim, ao invés de fundos oriundos do mercado de capitais, como se

\footnotetext{
${ }^{18}$ Veja-se a respeito Royer (2014).

${ }^{19}$ Ibidem. A Abecip teria participado de um "intenso trabalho de análise dos sistemas mundiais, com a finalidade de se buscar a melhor alternativa para ser adaptada à realidade brasileira”, com destaque para a "comitiva formada por representantes do sistema financeiro privado e público que, em março de 1995, foi aos Estados Unidos para conhecer o modelo de financiamento americano centrado na securitização".

${ }^{20}$ Ibidem.

${ }^{21}$ Royer, op. cit., p. 125. Royer, Fix e outros pesquisadores mostram, entretanto, que esses instrumentos não se disseminaram do mesmo modo e nas proporções atingidas nos EUA, pelo contrário. Pesquisas empíricas e análises teóticas são fundamentais, nesse sentido, e sugerem a necessidade de aprofundamento das especificidades da aplicação do modelo em formações socioespaciais diferentes. O debate brasileiro já dispõe de literatura a respeito. Além dos já citados, conferir os trabalhos de Daniel Sanfelici, Everaldo Melazzo, Rafael Cagnin, Lucia Shimbo, Beatriz Rufino, Raul Ventura Neto, Álvaro Pereira, Marcos Barcellos, Jeroen Klink, entre outros. Conferir ainda os trabalhos apresentados nos encontros da ANPUR e em seminários sobre o tema, como Financeirização e estudos urbanos: olhares cruzados Europa e América Latina, realizado em maio de 2016, no IAU-USP.
}

${ }^{22}$ Ibidem. 
alegava, a liquidez necessária para o funcionamento dos CRI teve como base, ao menos inicialmente, os recursos captados no funding cativo da poupança a baixo custo, ou seja, no FGTS. ${ }^{23} \mathrm{O}$ volume, contudo, é inexpressivo em relação ao total do crédito imobiliário emitido pelos bancos, mesmo considerando o crescimento recente (Royer, 2016). Esse resultado é mais um indicativo de que o relacionamento entre setor imobiliário e financeirização pode trazer resultados muito diferentes quando se considera o centro ou a periferia do sistema capitalista.

Parece claro que a multiplicação dos processos de securitização amplia sobremaneira a "disseminação das características do capital portador de juros" no sistema como um todo. Quando associados ao mercado imobiliário, especulativo por natureza, esses processos podem ter consequências tão drásticas quanto aquelas observadas na crise que completa agora uma década. A securitização, portanto, torna ainda mais fortes os liames entre mercado imobiliário e financeirização, ainda que suas consequências, como já mencionado, possam ser distintas a depender do espaço onde o aprofundamento dessa imbricação se dê. Agudiza também as contradições que surgem do tratamento da terra como puro ativo financeiro, as quais veremos na segunda seção do artigo, seguindo novamente a trilha de Harvey (2006). Antes, porém, falta-nos ainda tratar da construção, a atividade capitalista, geradora de valor, que é elemento constitutivo do setor imobiliário.

\section{Terra e construção}

Como já mencionamos, os terrenos são a base para a reprodução material e para a extração, e são também elementos necessários de toda produção e atividade humanas, funcionando então como espaço, como lugar e fazendo parte, por isso, daquilo que Marx chama de condições objetivas do processo de trabalho.

No entanto, quando a mercadoria é a própria construção, seja ela residencial ou não (fábricas, escolas, hospitais etc.), o relacionamento entre a terra e o processo de produção exibe singularidades que exigem algumas observações adicionais. $\mathrm{Na}$ produção da construção, a terra vai junto com a mercadoria (o que não acontece no caso da produção de outras mercadorias). A renda fundiária é, portanto, fundamento de um determinado ramo econômico; ela é suporte da atividade imobiliária. ${ }^{24}$ Ora, isso é "radicalmente diferente de pensar-se a propriedade e o uso da terra urbana como especulação desligada da produção real” (Oliveira, 1979, p. 15). À renda fundiária, relacionada à propriedade da terra nua, funde-se uma parcela relacionada com o progresso do desenvolvimento social que se denomina renda

\footnotetext{
${ }^{23}$ Sobre a importância dos recursos do FGTS na alavancagem do CRIs ver Royer (2016).

${ }^{24}$ Cf. a respeito o prefácio que Chico de Oliveira escreveu para o livro A produção capitalista da casa (e da cidade) no Brasil industrial, organizado por Ermínia Maricato (1982), que inclui texto de Rodrigo Lefèvre sobre renda da terra, além de outros importantes ensaios. A literatura sobre renda da terra urbana no Brasil e no exterior é vasta e variada, mas uma revisão ultrapassaria os limites deste artigo.
} 
imobiliária e que tem importância crescente na acumulação de capital (Marx, 1988, apud Tone, 2015, p. 33).25

As implicações dessa característica são muitas e ultrapassam os limites deste artigo. Pereira e Rufino argumentam, por exemplo, que se o preço da terra determinou, historicamente, em grande medida, o preço dos produtos imobiliários, quando a forma de produção imobiliária de mercado se fortalece, são os produtos imobiliários potenciais, em devir, que indicarão o preço da terra (2011, p. 75).

Outra singularidade do imobiliário reside na organização do trabalho no canteiro de obras. Em seu livro Canteiro e desenho, Sérgio Ferro (Ferro, 2006) ${ }^{26}$ explica a racionalidade produtiva do canteiro a partir da forma manufatureira de produção, tal como descrita por Marx, com a especificidade de que "na produção do espaço a manufatura é móvel e não seus produtos (Arantes, 2012, pp. 180-181). A construção é diferente de outras atividades produtivas e utiliza uma quantidade considerável de força de trabalho (Ball, apud Arantes, 2012, p. 183). Coriat propõe a denominação "forma-canteiro" para discutir a diferença entre a construção e a "forma-fábrica" (Ibidem, p. 183).

Essa quantidade de trabalho mobilizada na atividade da construção é frequentemente evocada como razão de políticas de geração de empregos, com pouca atenção para as condições de trabalho nos canteiros, marcados por longas jornadas de trabalho, baixos salários, altos índices de acidentes e elevada rotatividade. Nos EUA, estima-se que um terço dos trabalhadores da construção não seja nativo e que $40 \%$ deles sejam considerados ilegais (Arantes, 2012, p. 240). No Brasil, o caso do programa habitacional Minha Casa Minha Vida é emblemático. A empresa imobiliária que mais casas construiu no programa, beneficiando-se dos subsídios públicos, foi acusada pelo Ministério Público do Trabalho (MPT) de "prática de infração da ordem econômica através da supressão maciça, em larga escala, de direitos trabalhistas, com a consequente obtenção de expressiva redução do custo do trabalho e, portanto, de vantagem arbitrária sobre a concorrência". Entre as condutas ilícitas listadas pelo MPT estava a "submissão de trabalhadores a condições degradantes, análogas às de escravo”, por vários anos e em diversos empreendimentos no país. Enquanto isso, a empresa aumentou o lucro líquido em quase 15 vezes, entre 2007 (cerca de R \$ 42,8 milhões) e 2010 ( $\mathrm{R}$ \$ 634,4 milhões) ${ }^{27}$ e seu valor de mercado passou de $\mathrm{R} \$ 6,7$ milhões em setembro de 2007 para quase $\mathrm{R} \$ 10$ milhões em setembro 2010.

Essas considerações indicam que, quanto mais a produção capitalista vai sendo a responsável pela produção do espaço, tanto mais importante vão se tornando as rendas imobiliárias (que se aproximam da renda diferencial de tipo II de que trata Marx no capítulos XL a XLIV do Livro III de O Capital) perante as rendas

\footnotetext{
${ }^{25}$ Cf. Pereira, Paulo C. X. (1988).

${ }^{26}$ Publicado originalmente em 1976, o livro foi incluído como um capítulo da coletânea Sérgio Ferro: Arquitetura e trabalho livre, em 2006.

${ }^{27}$ Valores ajustados pelo IPCA para novembro de 2014.
} 
fundiárias, resultantes apenas das "dádivas da Natureza". Quanto mais o espaço é produzido pelo capital, tanto mais a renda, como figura da mais-valia, vai se amalgamando com o lucro e tornando indiscerníveis a apropriação de valor excedente gerado pela produção presente (lucro), da apropriação que tem como base o valor a ser gerado pela produção futura (renda), incorporado no preço do imóvel.

\section{A TERRA COMO PURO ATIVO FINANCEIRO E SUAS CONTRADIÇÕES}

A tese geral de Harvey é que "um dos triunfos do capitalismo foi forçar os proprietários da terra a um papel positivo para a acumulação como condição para sua sobrevivência" (2006, p. 366), mas isso tem um preço. Parte desse preço se objetiva na própria permanência da renda como forma de apropriação da mais-valia, renda essa que é, em princípio, antagônica à acumulação, podendo mesmo reduzir a produção de valor excedente. ${ }^{28} \mathrm{~A}$ outra parte desse preço está relacionada à natureza especulativa da terra como ativo: "A integração da propriedade da terra na circulação do capital portador de juros pode abrir a terra ao livre fluxo do capital, mas também a abre para o pleno jogo das contradições do capitalismo" (Harvey, 2006, p. 349).

Segundo Harvey (2006, pp. 360-362), o primeiro elemento do papel positivo da propriedade da terra para acumulação de capital foi indicado pelo próprio Marx, quando afirmou que a renda, ao invés de amarrar o homem à Natureza, vincula a exploração da terra à concorrência, possibilitando a racionalização da agricultura e a aplicação da ciência. Assim, ao "taxar" os superlucros nas terras mais férteis, os proprietários de terra funcionam como operadores da equalização da taxa de lucro entre os concorrentes capitalistas, arrendatários capitalistas incluídos. Com isso, ajudam a empurrar a produção capitalista em geral para o moto-perpétuo da caça de mais-valia relativa.

Para falar do segundo elemento desse papel positivo, é preciso inicialmente lembrar que nas formações anteriores ao capitalismo e mesmo no modelo de sociedade de classes da economia política originária (que refletia os inícios do capitalismo na Inglaterra e em outras partes da Europa Ocidental), os proprietários de terra ou comandam algum tipo de exploração direta da força de trabalho - tão limitada para o desenvolvimento das forças produtivas quanto a mais-valia absoluta - ou atuam involuntariamente no estímulo à busca de mais-valia relativa, mas de modo passivo, como recebedores de renda. Nesses casos, tínhamos a prevalência daquilo que Harvey chama de "o poder social da terra" sobre aquilo que ele chama de "o poder social do dinheiro" (Harvey, 2006, p. 366). Nessas formações, as considerações associadas secularmente à propriedade fundiária e que giram em torno de se-

\footnotetext{
${ }^{28}$ Se tiverem força suficiente, os proprietários de terra podem forçar o preço dos alimentos para a esfera dos preços de monopólio (não só acima do preço de produção, mas acima do próprio valor), elevando o tempo de trabalho necessário e reduzindo o tempo de trabalho excedente, que é a base da mais-valia.
} 
gurança, importância simbólica, tradição e prestígio é que tinham primazia. O "interesse fundiário" tinha uma certa autonomia e jogava um papel independente.

O desenvolvimento capitalista foi tirando da frente muitos desses empecilhos, mas, para Harvey, apenas a plena atuação do capital portador de juros é capaz de inverter o jogo e forjar um papel ativo para a propriedade privada da terra. $\mathrm{O}$ interesse fundiário em si, que na prática tem ainda relativa importância em certos lugares, bem como as vantagens relativamente permanentes para os proprietários de terra advindas de diferenças naturais ou de localização (rendas diferenciais) é que podem ossificar determinadas configurações do espaço e determinados usos da terra. Mas isso não acontece se o capital portador de juros fixa os preços dessas terras de acordo com rendas futuras esperadas crescentes. Para Harvey, "os proprietários de terra que tratam sua terra como puro ativo financeiro levam adiante exatamente essa tarefa" (2006, p. 368). Seu papel, nesse caso, não é de modo algum passivo. Ao forçarem a produção na terra a novas configurações, eles atuam no processo de reconfiguração geográfica, promovendo os melhores usos da terra do ponto de vista da concorrência e da acumulação, e antecipam as condições em que se dará a produção futura de mais-valia "condenando o trabalho futuro a níveis sempre crescentes de exploração” (Harvey, 2006, p. 368).

A atividade especulativa que tem a terra por objeto pode produzir ganhos enormes em reduzido espaço de tempo. Por isso, todas as armas são válidas quando se trata de embolsá-los. Uma forma bem conhecida é a ocultação de informação privilegiada. Quem detiver, por exemplo, alguma informação antecipada sobre investimentos em transporte em determinado lugar, os quais criarão inevitavelmente rendas diferenciais de localização (base para rendas imobiliárias crescentes), pode se beneficiar disso e auferir ganhos especulativos no comércio com a terra. Num escopo mais amplo, apostas em bairros inteiros, bem como os processos, intermediados pelo Estado, de transformação da cidade em mercadoria na busca de atrair novos investimentos, são todos momentos do jogo especulativo. ${ }^{29}$

Harvey lembra ainda que "a atratividade da terra como investimento (sua segurança e o prestígio que ela tradicionalmente confere a seus proprietários) sempre a tornaram vulnerável ao capital excedente" (2006, p. 348). Isso significa que quanto mais excesso de capital houver ou, dizendo de outro modo, quanto maior for a crise de sobreacumulação, tanto maior a probabilidade de a terra integrar o circuito geral da acumulação e se transformar em objeto de especulação. Ora, se a quadra atualmente vivida pelo capitalismo é, como quer o próprio Harvey, marcada justamente pela sobreacumulação e por uma permanente pletora de capitais monetários, é evidente que temos todas as condições para que o mercado de terras magnifique e eleve a um grau sem precedentes as "insanas formas de especulação"

\footnotetext{
${ }^{29}$ Entramos aqui no complexo terreno das discussões sobre o planejamento urbano nesta última quadra histórica do capitalismo. Foge do escopo deste trabalho uma discussão mais aprofundada desses fenômenos que são tratados, no Brasil, por Arantes, Maricato e Vainer (2000), Fix (2001, 2003), Compans (2005), Ferreira (2007), dentre vários autores.
} 
e "o auge das distorções" (os termos são de Marx) criados pelo crédito e pelo capital portador de juros. Tratar a terra como puro ativo financeiro, ao mesmo tempo em que coloca seu uso em linha com as necessidades do capital, pode ter também o resultado oposto, pois deixa o sistema sempre em suspenso, sempre prestes a sucumbir às correntes irracionais que a especulação desenfreada acaba por criar.

Ainda com relação ao papel positivo da propriedade privada da terra, Harvey lembra que as receitas dos proprietários de terra fazem parte das receitas gerais da burguesia (2006, pp. 365-366) e que sua devolução à circulação para utilização como capital monetário sugere um forte vínculo potencial entre a propriedade da terra, a atividade bancária e a acumulação. O direcionamento para a produção do fluxo de receitas originado da terra (bem como, podemos complementar, dos ganhos monetários derivados da especulação) de fato poderia servir de elemento dinamizador da acumulação, engrossando o crédito a ser direcionado aos investimentos em ativos reais.

Outros vínculos podem também existir, como mostrou o boom imobiliário que precedeu a crise de 2007-2008. A especulação com MBS alimentou a indústria da construção - a produção de casas aumentou segundo os dados do Census Bureau - uma das mais importantes da economia do ponto de vista de sua contribuição para o Produto Interno Bruto (PIB) e para o emprego (Fix, 2011).

Todavia, é preciso lembrar, que a aplicação em crédito para a produção depende de muitas outras variáveis, que podem se movimentar em sentido contrário ao necessário, principalmente num momento histórico como o atual, marcado pela sobreacumulação. Já o direcionamento desses recursos para o financiamento do consumo parece mais provável, tendo como resultado necessário a acumulação de passivos por parte das famílias, um elemento característico da financeirização.

Finalmente não se pode esquecer que a terra faz parte também do fundo de consumo. O que se chamou de "interesse fundiário" mescla-se aí com as necessidades de abrigo e moradia de todas as classes. Pequenos proprietários rurais ou urbanos podem, por isso, se colocar como ossos duros de roer para o dinamicismo do capital portador de juros que circula no mercado imobiliário. Mas ele vence quase sempre, por meios lícitos ou ilícitos. A especulação complica ainda mais as coisas, pois opera tendencialmente no sentido da elevação do preço das terras e na assim chamada "gentrificação" das áreas mais bem localizadas e mais bem-dotadas de infraestrutura urbana das grandes cidades. Mais do que um resultado da demanda por imóveis das classes mais abastadas e que desejam o símbolo de status que as áreas enobrecidas podem propiciar, a gentrificação é muitas vezes o resultado de um planejamento de médio ou longo prazo do próprio negócio imobiliário. Smith (1996) mostra como o desinvestimento e a degradação quase programados da região do Lower East Side de Nova York, no final dos anos 1970, resultou num bem-sucedido plano de gentrificação da área, com a consequente expulsão de seus moradores originais (imigrantes, desempregados etc.). ${ }^{30}$

\footnotetext{
${ }^{30}$ Sobre o tema sugerimos também o documentário My Brooklyn, de Kelly Anderson. Cf. em http:// www.mybrooklynmovie.com/.
} 
A discriminação socioespacial costuma por isso acentuar a desigualdade social e contribuir sobremaneira para a criação de áreas de miséria e pobreza em paralelo aos enormes ganhos na especulação com terras e imóveis. Por fim, dado o valor normalmente inatingível das residências para os rendimentos derivados dos salários, os trabalhadores sucumbem inexoravelmente ao mercado de crédito, com todo seu séquito de consequências. A mística em relação à casa própria não só tem efetividade ideológica ao colocar a classe trabalhadora do lado da defesa da propriedade privada, como tem efetividade, por assim dizer, prática, ao amarrar os trabalhadores, por longos períodos de tempo, pela via do sistema de crédito, seja qual for sua modalidade (hipoteca, alienação fiduciária), ao sucesso dos negócios capitalistas.

Em tempos de aprofundamento das relações entre o setor imobiliário e o processo de financeirização, as consequências desse complexo de relações que envolve a produção das residências como mercadoria podem ir além do crescimento da desigualdade e do sequestro da consciência de classe produzido pela necessária escravização das rendas do trabalho ao pagamento dos juros sobre o financiamento do consumo de um bem que traz em seu preço a incorporação de rendas imobiliárias cada vez mais importantes. Elas podem reforçar outros mecanismos de desigualdade como a discriminação social associada, por exemplo, ao racismo e à xenofobia.

Análise especializadas dos despejos mostram que os bairros norte-americanos foram desigualmente atingidos na crise de 2007-2008. Os empréstimos subprime eram concentrados em alguns distritos das cidades, geralmente aqueles com maior percentual de moradores negros ou considerados "latinos"; e foram esses justamente os mais atingidos pelas execuções hipotecárias e despejos forçados quando os imóveis foram retomados pelos bancos. As análises que desconsideram a localização desses empréstimos no território e dos despejos são, por isso, insuficientes para revelar a realidade das regiões mais atingidas, alvos da discriminação racial que, segundo alguns autores, caracterizou historicamente o sistema de crédito norte-americano. ${ }^{31} \mathrm{~A}$ concentração de despejos deixou bairros com alto percentual de imóveis vazios, com portas e janelas vedadas por tapumes e avisos de despejo afixados, o que derrubou ainda mais o preço das casas. Essa devastação gerou um efeito espiral que acentuou ainda mais a queda de preços, dificultando o refinanciamento das dívidas mesmo das famílias que inicialmente não haviam sido afetadas porque tinham condições melhores de pagamento. Segundo o relatório National Fair Housing Alliance, de 2012, essa foi a "maior perda de riqueza dessas comunidades na história moderna", resultando no aumento desigualdade de riqueza entre brancos e negros. ${ }^{32}$

Tratar a terra como puro ativo financeiro constitui de fato, como quer Harvey, uma tendência inexorável desse tipo de bem, em particular quando o sistema padece

\footnotetext{
${ }^{31}$ Cf. E. Wyly e G. Dymski, entre outros.

${ }^{32}$ Laura Gottesdiener. “The Great Eviction. The landscape of Wall Street's creative destruction”. The Nation, agosto de 2013. Disponível em: https:/www.thenation.com/article/great-eviction/.
} 
de sobreacumulação crônica e é comandado pela financeirização. Mas, como a terra não se reduz a isso (a ser um ativo financeiro), as consequências dessa tendência são muito mais complexas, seja para o aprofundamento de desigualdades socioeconômicas que se refletem na configuração do espaço, em particular o espaço urbano, seja pela condição de extrema vulnerabilidade que conferem ao próprio processo de acumulação. As especificidades de cada país e seu papel dentro do capitalismo global tornam distintas essas consequências, mas sempre no sentido de tornar mais aguçadas as contradições inerentes a esse sistema. A produção do espaço construído seguindo a régua e o compasso da lógica da acumulação funciona ela própria como elemento poderoso de aprofundamento dessas antinomias, como deu mostras de sobra a crise deflagrada a partir do mercado imobiliário norte-americano em 2008.

\section{REFERÊNCIAS}

ARANTES, Otília; Maricato, Erminia; Vainer, Carlos. A cidade do pensamento único. Petrópolis, Vozes, coleção Zero à Esquerda, 2000.

ARANTES, Pedro. Arquitetura na era digital-financeira: desenho, canteiro e renda da forma. São Paulo, Editora 3, 2012.

BOYER, Robert. Teoria da regulação - Uma Análise Crítica. São Paulo, Nobel, 1990.

BRAGA, José C. de S.. Temporalidade da riqueza - Teoria da dinâmica e financeirização do capitalismo. Campinas, IE-Unicamp, coleção Teses, 2000.

CARLOS, Ana Fani. A condição Espacial. Editora contexto, São Paulo, Contexto, 2011.

CHESNAIS, François. “Introdução Geral”. In: CHESNAIS, F. (org.) A mundialização Financeira. São Paulo, Xamã, 1998.

CHESNAIS, François. “O Capital portador de juros: acumulação, internacionalização, efeitos econômicos e políticos”. In: CHESNAIS, F (org.) A finança mundializada. São Paulo, Boitempo. 2005.

CHESNAIS, François. "A proeminência da finança no seio do capital em geral”. In: CHESNAIS, François. et ali (org.). A finança capitalista. São Paulo, Alameda, 2010.

CHESNAIS, François. Finance capital today. Leiden, Boston, Brill (Historical Materialism Book series), 2016.

COMPANS, Rose. Empreendedorismo urbano: entre o discurso e a prática. Editora Unesp; 2005.

FERREIRA. João S. W. O mito da cdade global. O papel da ideologia na produção do espaco urbano, São Paulo: Vozes, 2007.

FERRO, Sérgio. Arquitetura e trabalho livre. São Paulo, Cosac Naify, 2006.

FIX, Mariana. Financeirização e Transformações Recentes no Circuito Imobiliário no Brasil. IE- Unicamp, Tese de doutorado, 2011.

FIX, Mariana. São Paulo Cidade Global: Fundamentos de uma miragem. São Paulo, Boitempo, 2007.

FIX, Mariana. Parceiros da exclusão: duas histórias da construção de uma "nova cidade" em São Paulo: Faria Lima e Água Espraiada. São Paulo: Boitempo, 2003.

HARVEY, David. Limits to capital. New York, Verso, 2006.

HERRERA, Rêmy. “O Capital Fictício no Centro da Crise”. In: GOMES, Helder. (org.), Especulação e Lucros Fictícios: formas parasitárias da acumulação contemporânea. São Paulo, Outras Expressões, 2015.

MARICATO, Erminia. Produção capitalista da casa (e da cidade) no Brasil. 1. ed. São Paulo: Alfa-Ômega, 1979.

OLIVEIRA, Francisco de. Prefácio. In: MARICATO, Erminia. Produção capitalista da casa (e da cidade) No Brasil. 1. ed. São Paulo: Alfa-Ômega, 1979. 
MARX, Karl. “O rendimento e suas fontes”. In: Marx, São Paulo, Abril Cultural, coleção “Os Pensadores", 1983.

MARX, Karl.. O capital, Volume I, Tomo I. In: Marx, São Paulo, Abril Cultural, coleção “Os Economistas", 1983.

MARX, Karl.. O capital, Volume I, Tomo II. In: Marx, São Paulo, Abril Cultural, coleção “Os Economistas", 1984.

MARX, Karl.. O capital, Volume III, Tomo I. In: Marx, São Paulo, Abril Cultural, coleção "Os Economistas", 1984

PAULANI, L. Brasil delivery. São Paulo, Boitempo, 2008.

PAULANI, L.. A Inserção da Economia Brasileira no Cenário Mundial: uma reflexão sobre a situação atual à luz da história. Boletim de Economia e Política Internacional, IPEA, nº 10, 2012.

PAULANI, L. Acumulação Sistêmica, Poupança Externa e Rentismo: observações sobre o caso brasileiro. Estudos Avançados (IEA-USP), vol. 27, nº77, 2013.

PAULANI, L. Acumulação e Rentismo: resgatando a teoria da renda de Marx para pensar o Capitalismo Contemporâneo. Revista de Economia Política, vol. 36, número 3, 2016.

PEREIRA, Paulo C. X.; RUFINO, Maria Beatriz C. Segregação e produção imobiliária na metrópole latino-americana: um olhar a partir da cidade de São Paulo. IN: LENCIONI, Sandra; VIDAL-KOPPMANN, Sonia, HIDALGO, Rodrigo e PEREIRA, Paulo C. X.. Transformações sócio-territoriais nas metrópoles de Buenos Aires, São Paulo e Santiago, 2011.

RIBEIRO, Luiz César de Q. Dos Cortiços aos Condomínios Fechados: as formas de produção da moradia na cidade do Rio de Janeiro. Civilização Brasileira: Rio de Janeiro: IPPUR, UFRJ: FASE, 1997.

RODRIGUES, Arlete M. Ciência e ação política: por uma abordagem crítica. In: OLIVEIRA, Floriano José Godinho de; FREIRE, Desirée G.; MASCARENHAS, Gilmar; OLIVEIRA, Leandro D. de. (Orgs.). Geografia urbana: ciência e ação política. Rio de Janeiro: Editora Consequência, 2014, pp. 21-44, 2014.

ROLNIK, Raquel. Guerra dos lugares. São Paulo: Boitempo, 2015.

ROYER, Luciana O. Financeirização da política habitacional. São Paulo, Annablume, 2014.

ROYER, Luciana. O FGTS e o mercado de títulos de base imobiliária: relações e tendências, Cadernos Metrópole., São Paulo, v. 18, n. 35, pp. 33-51, abr 2016.

SEABRA, Odette C. L. Os meandros dos rios nos meandros do poder: Tietê e Pinheiros: Valorização dos Rios e das Várzeas na cidade de de São Paulo. Tese, FFLCH-USP, 1987.

SMITH, Neil. The New Urban Frontier Gentrification and the Revanchist City. Londres, Routledge, 1996.

TONE, Beatriz. São Paulo Século XXI. Valorização imobiliária e dissolução urbana. Tese de doutoramento. FAUUSP, 2015.

VILLAÇA, Flávio. A terra como capital (ou a terra-localização). Revista Espaço \& Debates. Ano V n. 16, 1985.

WYLY, Elvin K.; Atia, Mona; Foxcroft, Holly; Hamme, Daniel J.; Phillips囚watts; Kelly. American home: predatory mortgage capital and neighbourhood spaces of race and class exploitation in the united states, Geografiska Annaler: Series B, Human Geography, 88:1, 105-132, DOI: 10.1111/ j.0435-3684.2006.00208, 2006. 